Schmitterer, Alexandra M. A.; Schroeder, Sascha

\title{
Effects of reading and spelling predictors before and after school entry. Evidence from a German longitudinal study
}

formal und inhaltlich überarbeitete Version der Originalveröffentlichung in:

formally and content revised edition of the original source in:

Learning and instruction (2019) 59, S. 46-53

Bitte verwenden Sie in der Quellenangabe folgende URN oder DOI /

Please use the following URN or DOI for reference:

urn:nbn:de:0111-pedocs-193853

10.25656/01:19385

https://nbn-resolving.org/urn:nbn:de:0111-pedocs-193853

https://doi.org/10.25656/01:19385

\section{Nutzungsbedingungen}

Dieses Dokument steht unter folgender Creative Commons-Lizenz: http://creativecommons.org/licenses/by-nc-nd/4.0/deed.de - Sie dürfen das Werk bzw. den Inhalt unter folgenden Bedingungen vervielfältigen, verbreiten und öffentlich zugänglich machen: Sie müssen den Namen des Autors/Rechteinhabers in der von ihm festgelegten Weise nennen. Dieses Werk bzw. dieser Inhalt darf nicht für kommerzielle Zwecke verwendet werden und es darf nicht bearbeitet, abgewandelt oder in anderer Weise verändert werden.

Mit der Verwendung dieses Dokuments erkennen Sie die Nutzungsbedingungen an.

\section{Terms of use}

This document is published under following Creative Commons-License: http://creativecommons.org/licenses/by-nc-nd/4.0/deed.en - You may copy, distribute and transmit, adapt or exhibit the work in the public as long as you attribute the work in the manner specified by the author or licensor. You are not allowed to make commercial use of the work or its contents. You are not allowed to alter, transform, or change this work in any other way.

By using this particular document, you accept the above-stated conditions of use.

\section{Kontakt / Contact:}

peDOCS

DIPF | Leibniz-Institut für Bildungsforschung und Bildungsinformation Informationszentrum (IZ) Bildung

E-Mail: pedocs@dipf.de

Internet: www.pedocs.de 
Running Head: READING PREDICTORS ACROSS SCHOOL ENTRY

Effects of Reading and Spelling Predictors Before and After School Entry:

Evidence from a German Longitudinal Study

Alexandra M. A. Schmitterer1 and Sascha Schroeder2

1DIPF | Leibniz Institute for Research and Information in Education, Frankfurt am Main 2Max Planck Institute for Human Development, Berlin

Disclaimer: This PDF document is a copy of the final version of the manuscript that was subsequently accepted for publication by the Elservier Journal "Learning and Instruction". This manuscript is a peer-reviewed post-print version, that has not been subjected to any additional copy-editing or journal-specific formatting.

Cite this article as:

Schmitterer, A. M.A., \& Schroeder, S. (2019). Effects of reading and spelling predictors before and after school entry: Evidence from a German longitudinal study. Learning and Instruction, 59, 46-53. doi: 10.1016/j.learninstruc.2018.09.005 


\title{
Running Head: READING PREDICTORS ACROSS SCHOOL ENTRY
}

\begin{abstract}
Previous studies indicate that the effectiveness of reading and spelling predictors in transparent orthographies is affected by the onset of literacy training at school entry. In this longitudinal study with 65 German speaking children, the effects of literacy predictors on reading and spelling abilities were compared before and after school entry. Phonological awareness, letter sound knowledge, and rapid naming were assessed before and after school entry. In addition, reading and spelling abilities were assessed at the end of first grade. Path model analyses showed that letter sound knowledge before school entry predicted reading and spelling at the end of first grade, while rapid naming after school entry predicted reading but not spelling abilities. This study shows that the onset of schooling influenced the predictability of early literacy predictors and indicates that with the onset of formal literacy education, predictors representing automaticity in serial processing increase in significance for reading abilities.
\end{abstract}

Keywords: predictors; reading acquisition; spelling acquisition; longitudinal; school entry 


\section{Running Head: READING PREDICTORS ACROSS SCHOOL ENTRY}

\section{Introduction}

Reading and writing are two important cultural skills that support children's independence and foster social integration and career opportunities throughout the life span (Cunningham \& Stanovich, 1997). Several precursor skills have been identified across languages which are able to predict early reading and spelling abilities. Early word reading or decoding abilities in turn are precursors for more advanced reading abilities like reading comprehension (see i.e., Caravolas et al., 2012; Van Viersen, de Bree, Zee, Maassen, van der Leij, de Jong, 2018).

The most regularly identified predictors of early reading abilities are phonological awareness (i.e., rime awareness, phoneme awareness), letter sound knowledge and rapid naming (e.g., Caravolas, Lervag, Defior, Málková, \& Hulme, 2013; Caravolas et al., 2012; Castles \& Coltheart, 2004;Georgiou, Parrila, Cui, Papadopoulus, 2013; Georgiou, Papadopoulus, \& Kaizer, 2014; Hulme, Nash, Gooch, Lervåg, \& Snowling, 2015; Muter, Hulme, Snowling, \& Stevenson, 2004; Näslund \& Schneider, 1996; Schatschneider, Fletcher, Francis, Carlson, \& Foorman, 2004; Leppänen, Aunola, Niemi, \& Nurmi, 2008; Lervag, Lyster, \& Hulme, 2012; Torppa, Lyytinen, Erskine, Eklund, \& Lyytinen, 2010; Ziegler et al., 2010). Phoneme awareness, letter sound knowledge and rapid naming have, furthermore, been connected to spelling (Caravolas, Hulme, \& Snowling, 2001; Caravolas et al., 2012; Moll et al., 2014).

In addition, it is known that various subcomponents of early reading (i.e., word reading ability, reading fluency) and spelling abilities are predicted by different predictors (Ziegler et al., 2010; Leppänen et al., 2008; Moll et al., 2014; Muter et al., 2004; Van Viersen, et al., 2018). For example, early word reading and spelling abilities are predicted by phonological awareness and letter sound knowledge (e.g., Caravolas et al., 2001; Caravolas et 


\section{Running Head: READING PREDICTORS ACROSS SCHOOL ENTRY}

al., 2012; Caravolas et al., 2013) while reading fluency is additionally explained by rapid naming (e.g., Moll et al., 2014; Ziegler et al., 2010; Van Viersen et al., 2018).

The significance of phonological awareness, letter sound knowledge and rapid naming on reading and spelling abilities is consistent across alphabetic languages. However, the trajectories of reading and spelling acquisition differ as a function of language transparency (Caravolas et al., 2013; Caravolas et al., 2012; Ziegler et al., 2010; Ziegler \& Goswami, 2005) and educational environment (Holopainen, Ahonen, Tolvanen, \& Lyytinen, 2000). For example, the effect of phonological awareness on reading and spelling has been found to be stronger in opaque than transparent orthographies (Leppänen et al., 2008; Mann \& Wimmer, 2002; Moll et al., 2014; Ziegler et al., 2010).

While evidence on the trajectories of literacy development in different orthographies is increasing (i.e. Caravolas et al., 2013; Moll et al., 2014), studies on the influence of changes in the educational environment on the trajectory of predictors and literacy outcomes are still scarce. Most studies on reading and spelling predictors have been conducted after the onset of formal literacy education (Caravolas et al., 2001; Caravolas et al., 2012; Moll et al., 2014; Murphy \& Farquhason, 2016; Ziegler et al., 2010) and longitudinal studies which study development across school entry did not compare the predictability of different precursor skills before and after school entry (i.e., Hulme et al., 2015; Torppa et al., 2010).

However, there is some evidence that suggests that the effects of precursor abilities vary as a function of institutional change, especially in educational environments where educational traditions differ strongly before and after school entry. For example, Caravolas and colleagues (2013) studied growth patterns of word-picture-matching abilities in Czech, Spanish and English-speaking children. During the course of the study, Czech and Spanish speaking children entered school, while English speaking children already attended school. Results show that growth patterns increased strongly in Czech and Spanish speaking children 


\section{Running Head: READING PREDICTORS ACROSS SCHOOL ENTRY}

as a function of school entry but remained linear in English speaking children. In line with this finding, the predictors explaining these growth patterns might also change as a function of school entry.

For example, letter sound knowledge, a common predictor of reading abilities (i.e., Castles \& Coltheart, 2004; Leppänen et al., 2008; Schatschneider et al., 2004), is the bedrock of early alphabetic training in the first years of reading and spelling education. However, it is not clear how and when letter knowledge is acquired and how it develops in educational environments in which it is not mandatory to train letter knowledge before school entry, (i.e., Goswami et al., 2005; Leppännen et al., 2008; Mann \&Wimmer, 2002; Treiman \& Kessler, 2014). It can be expected, that letter knowledge is an important predictor of reading and spelling abilities, especially in transparent orthographies, in which children rely on phonemebased processing early in the reading acquisition process (i.e., Ziegler \& Goswami, 2005). However, variability in letter sound knowledge is likely to decrease rapidly after school entry, when formal instruction of grapheme-phoneme correspondences begins and, thus, the influence of letter sound knowledge as a predictor of reading and spelling should become less important.

The opposite trajectory would be expected for predictors that are directly connected to cognitive processing mechanisms in reading or spelling and, thus, share a reciprocal relation with those abilities. For example, the relation between rapid naming and reading has been explained by the shared nature of serial processing in both abilities (Georgiou et al., 2013). This type of processing is likely to be fostered by reading acquisition and, thus, should increase in importance with the onset of formal reading instruction. It is unclear, however, whether the same trajectory can also be observed with regard to spelling: Studies with children in 4th grade (Moll et al., 2014) suggest that rapid naming is a significant predictor of 


\section{Running Head: READING PREDICTORS ACROSS SCHOOL ENTRY}

spelling, but there are no comparable studies investigating the predictive effects of rapid naming on spelling at earlier stages of development.

A similar developmental trajectory can be expected for children's phonological awareness skills. It is well established that the introduction to letters in school fosters phoneme awareness (Castles \& Coltheart, 2004; Lervag et al., 2012; Mann \& Wimmer, 2002) and beginning reading in transparent orthographies typically relies heavily on phoneme-based processing (not rime-based processing; Goswami, Ziegler, \& Richardson, 2005). Phoneme awareness has been identified as an early predictor of spelling abilities in English (Caravolas et al., 2001), but, again, there are no comparable studies with children that do not receive literacy training before school entry. This might be partially due to the fact that phoneme awareness is particularly difficult to assess in these particular circumstances (Castles \& Coltheart, 2004; Mann \& Wimmer, 2002). In contrast to phoneme awareness, rime awareness, which should be well developed even before school entry (Castles \& Coltheart, 2004; Mann \& Wimmer, 2002) should decrease in its influence on reading abilities, although it is unclear whether this also holds for spelling.

In summary, it is likely that the effects of different precursor abilities on reading and spelling skills diverge before and after school entry in transparent orthographies and in educational environments in which no strong emphasis is placed on teaching literacy skills before school entry. However, the question how these precursor skills develop and at which time they are particularly important for the development of later reading and spelling skills is of high practical relevance. The aim of this study was, thus, to compare effects of predictors of reading abilities before and after school entry in children that were learning to read in a transparent orthography, in an educational environment were literacy training differs strongly before and after school entry. In addition, as predictive effects on spelling have not been 


\section{Running Head: READING PREDICTORS ACROSS SCHOOL ENTRY}

studied extensively in transparent languages, we also included children's early spelling skills as an additional outcome variable.

We conducted a study with young German children, who grow up in an educational environment with no obligation to teach literacy skills (i.e. letter-sound-correspondences) before school entry. We assessed rime awareness, phoneme awareness, letter sound knowledge and rapid naming as predictors at two time points before and one time point after school entry. Fundamental (word-picture-matching) and advanced (reading fluency) reading abilities as well as spelling abilities were assessed at a fourth time point at the end of first grade. We investigated whether predictors were stable across time and compared their effects on reading and spelling abilities before and after school entry using path model analysis. We assumed that predictive effects of letter sound knowledge and rime awareness on reading abilities decrease across school entry, while effects of phoneme awareness and rapid naming would increase. Furthermore, we explored the development of predictive effects on spelling.

\section{Method}

\subsection{Participants}

Data reported here are part of the longitudinal project PLAiT, which investigated the literacy development of 104 young children across school entry. The children were recruited from seven Early Childhood Education and Care (ECEC) institutions in Berlin, Germany. A signed consent form of a primary care giver was a necessary condition for participation.

In Germany there is no grade-system before school entry. Children start first grade with school entry. Educators in ECEC institutions have an unsolicited guideline with regard to teaching contents, that, at the time of the study, did not include teaching reading, letters or phonological awareness but text familiarity (i.e., contact to text, joined picture-book reading sessions; Senatsverwaltung für Bildung, Jugend und Wissenschaft, 2014). Teachers in elementary school, on the contrary, follow a well-defined curriculum that includes teaching 


\section{Running Head: READING PREDICTORS ACROSS SCHOOL ENTRY}

letter-sound correspondences (phonics approach), reading, and spelling (i.e., Senatsverwaltung für Bildung, Jugend und Wissenschaft, 2017).

Background information (parental questionnaire) and general language and cognitive abilities of children were collected six months prior to the first assessment (T0). Various reading predictors were assessed ten and four months before school entry (T1-T2) and two months after school entry (T3). Literacy abilities were assessed ten months after school entry (T4).

Drop-out rates due to organizational reasons (i.e., moving away, not able to participate at one or more of the measurement points due to absence or illness) were in a range that is typical for longitudinal studies with kindergarten children: Only 17 children (16\% overall, i.e. $\sim 3-5 \%$ at each measurement points) dropped out across the five measurement points (T0T4). However, school entry in Berlin is only loosely regulated and parents have the option to decide whether their child will enter school at the age of 5,6 or 7. Although all parents indicated that they intend to send their children to school at age 6 at the beginning of the study, parents of 22 children eventually changed their decision. Differences between children that dropped out due to common reasons, children that dropped out due to school entry related decisions and children that entered school are provided in Tables S1 in the supplemental material.

The remaining 65 children ( 36 boys) completed the entire set of tasks at all time points. Those children's mean age at the assessments was $5 ; 4(S D=3.04)$ at $\mathrm{T} 1,5 ; 10(S D=$ $3.15)$ at $\mathrm{T} 2,6 ; 4(S D=3.15)$ at $\mathrm{T} 3$ and $7 ; 0(S D=3.14)$ at $\mathrm{T} 4$. Children were tested in individual sessions. Before school entry, children were assessed in a quiet room in the ECEC institution they attended (T1 - T2). Children entered one of over 30 schools after T2. Testing then took place at our research institute $(79 \%)$, in a quiet room at the school the child attended (15\%) or at the child's home (6\%) at T3 and T4. 


\section{Running Head: READING PREDICTORS ACROSS SCHOOL ENTRY}

Education of children's mothers was high with $74 \%$ of the mothers having a university degree (bachelor or higher). Most children (82\%) were monolingual, 12\% were bilingual, including German as one of their first languages and 6\% spoke German as a second language. Regarding children's general cognitive abilities, all children scored within two standard deviations of the population mean in standardized nonverbal intelligence (BUEVA-III; Esser \& Wyschkon, 2016) and vocabulary assessments (PDSS; Kauschke \& Siegmüller, 2009).

\subsection{Measures}

Outcome measures were assessed at T4, predictors were assessed at T1 through T3. Apart from rapid naming, the test score of all tasks was the number of correct responses. Task difficulties were age appropriate and reliabilities were acceptable to good (see Table 1).

2.2.1. Outcome measures. Picture-word reading abilities, reading fluency and spelling were measured using standardized tests. For picture-word-matching, children's word reading abilities were assessed with the WLLP-R (Schneider, Blanke, Faust, \& Küspert 2011). In this test, children were asked to correctly assign as many words as possible to one of four pictures within five minutes. Reading fluency was measured with a standardized speeded assessment (SLRT-II; Moll \& Landerl, 2010). Children were presented with a list of 156 words and were asked to read as many words out loud as possible in one minute. Spelling was assessed using the HSP 1+ (May, Vieluf, \& Malitzky, 2002). Children were asked to write down 9 dictated words and one dictated sentence. The number of correctly spelled graphemes served as the outcome variable.

2.2.2. Predictors. Rime awareness, phoneme awareness, letter sound knowledge, and rapid naming, were assessed to measure children's ability to access phonological, orthographic information as well as the degree of automaticity in serial processing.

Rime awareness was assessed with a computerized rime judgment task (i.e., Bradley \& Bryant, 1978; Wagensveld, van Alphen, Segers, \& Verhoeven, 2012). Children were 


\section{Running Head: READING PREDICTORS ACROSS SCHOOL ENTRY}

presented with two words and had to decide whether the words rhymed or not. They indicated their response by pressing a red key if the words did not rhyme and a green key if the words did rhyme.

Phoneme awareness was assessed with a computerized version of the vowel length discrimination task of the BAKO 1-4 standardized inventory of phonological predictor abilities with regard to reading in elementary grades 1-4 (Basiskompetenz für Lese- und Rechtschreibleistung; Stock, Marx, \& Schneider, 2003). The task was adapted for preschool children by presenting the stimuli in a forced decision design with two items per trial instead of an odd-one-out task with 5 items per trial to reduce working memory load. Children were asked to judge which one of two presented pseudowords sounded longer. Differences in length were manipulated with different vowel lengths. Words were presented on a laptop, children indicated their answers with oral responses and the experimenter logged in the answer.

Letter sound knowledge was assessed with a computerized task. Children heard 16 phonemes that have a unique correspondence to letters in German (e.g., /a:/ = A/a). Both upper- and lower-case letters were presented and children thus heard the sounds twice, resulting in 32 trials overall. They were asked to identify the letter out of a set of two letters that represented the sound. The two letters were presented on the left and right on a screen and children indicated their response by pressing a key on a keyboard.

The degree of automaticity in serial processing during word retrieval was assessed with a rapid naming task of objects (Pauly, Linkersdörfer. Lindberg, Woerner, Hasselhorn, \& Lonnemann, 2011). Children were asked to name 18 items in two lines of objects as fast as possible. Items consisted of six objects that were each presented three times in a randomized order. The number of errors and naming speed was recorded. The dependent variable was the number of correctly named items per second. 


\section{Running Head: READING PREDICTORS ACROSS SCHOOL ENTRY}

\subsection{Measurement invariance of predictor variables}

An important assumption of all longitudinal models is that variables assessed at different time points represent the same underlying construct, i.e. measurement invariance over time. In order to formally test this assumption with regard to the four predictor variables used at measurement points T1-T3, we estimated confirmatory factor analysis models (Cheung \& Rensvold, 2002). To do this, one unconstrained model and four constrained models were estimated, one for each predictor variable. In the unconstrained model, the three measurements of each predictor variable (from T1-T3) were assumed to load on one common latent factor, i.e. the model comprised four latent factors, one for each predictor variable. Importantly, however, the factor loadings were free and allowed to differ between the three measurement points. By contrast, in each of the constrained models, these factor loadings were assumed to be equal, in line with the assumption of measurement invariance over time. By comparing the constrained models with the unconstrained model, it is therefore possible to test the validity of this assumption.

The unconstrained model fitted the data well, $\chi_{2}(48)=54.37, p=.25$, RMSEA $=0.05$ $[0.000,0.097], \mathrm{CFI}=0.97, \mathrm{SRMR}=0.07$. More importantly, none of the constrained models decreased the fit of the model significantly, $\chi_{2}^{2}(2)=54.8$ (rime awareness) -57.8 (lettersound-knowledge); $\Delta \chi_{2}(2)=0.40-3.43, p=.18-.82$. This indicates that for all four predictor variables the assumption of measurement invariance over time was warranted, i.e. the tests measured the same underlying construct at all measurement points with similar discriminability.

\subsection{Children's early reading abilities}

To test whether some children were able to read before they entered school, we additionally assessed children's word-picture-matching skills (WLLP-R; Schneider et al., 2011) two months after school entry (T3: $\alpha=.97)$. On average, only very few words were 


\section{Running Head: READING PREDICTORS ACROSS SCHOOL ENTRY}

recognized $(M=12.64, S D=1.34)$ and $34 \%$ of children were not able to identify at least one word correctly. In addition, an adapted computerized version of the same task was also used with the children four months prior to school entry. Children were presented with a written word and a target as well as a distractor picture (phonological or semantic) in a forceddecision design. All items were based on the original standardized task. Children responded by pressing a key on the left for the left picture and a key on the right for the right picture. Children on average performed at chance level in this task, $M=0.45 \%, S D=0.23 \%$. Both findings indicate that children were not able to read before or directly after entering school.

\subsection{Procedure}

At each assessment, children completed all administered tasks within one session that lasted between 45 and 60 minutes. All sessions followed a similar procedure. Children were invited to go on a treasure hunt. Each task brought them closer to the treasure. The session started with standardized listening and paper-pencil tasks (word-picture-matching, spelling) and ended with a series of computerized tasks (letter sound knowledge, rime awareness, phoneme awareness, reading fluency and rapid naming). At the end, of each session, children received a small toy for their participation.

\section{Results}

\subsection{Preliminary analyses}

All analyses were conducted in R (version 3.3.2). Descriptive statistics and reliabilities of outcome measures and predictors are presented in Table 1. Skewness and kurtosis for all variables are reported in Table S2 in the supplemental material. For outcome variables both raw and standardized values were available and we used standardized values in the analyses.

Moreover, an outlier analysis with boxplots was conducted in two steps. First data points that lay outside 2.5 interquartile range of the lower quartile or above 2.5 interquartile 


\section{Running Head: READING PREDICTORS ACROSS SCHOOL ENTRY}

range of the upper quartile were identified. There were no outliers in outcome variables. With regard to predictors data points were only excluded, if a child had more than one outlying observation for the same skill. According to this definition, there were no outliers. Thus, no data points were discarded.

Finally, correlations between measures were calculated per time point, across time points (cross-level effects of predictors) and with regard to the predictive effects of predictors at $\mathrm{T} 1$ and $\mathrm{T} 3$ on reading and spelling skills at T4 (see Table S3 in the supplemental material).

\subsection{Path model analysis}

We specified path models using the \{lavaan package (Rosseel, 2012) and robust maximum likelihood estimation. No model trimming was applied and all models comprised all effects between all variables unless specified otherwise. For the sake of clarity, however, we only report significant effects.

\subsubsection{Predictive Effects of Predictors Before School Entry on Outcome Variables}

In a first model (Model 1), we used only variables at T1 as predictors of children's literacy abilities at the end of first grade, without taking the other measurement points into account (see Figure 1). Thus, this model focused on the question which early literacy predictors are related to later literacy abilities. This model is identical to a multiple regression model with T1 variables as predictors and T4 literacy skills as outcomes. It is, therefore, saturated and the fit of the model cannot formally be evaluated.

\section{[Figure 1]}

We found that word-picture matching abilities were predicted by early letter sound knowledge $(\beta=.39, S E=0.10, t=3.81, p<.001)$. Reading fluency was predicted by phoneme awareness $(\beta=.25, S E=0.10, t=2.64, p<.01)$ and, to a larger extent, by letter sound knowledge $(\beta=.36, S E=0.10, t=3.51, p<.001)$. Spelling ability was strongly predicted by letter sound knowledge $(\beta=.51, S E=0.10, t=5.02, p<.001$; see Figure 1$)$. The 


\section{Running Head: READING PREDICTORS ACROSS SCHOOL ENTRY}

amount of explained variance was substantial for each of the three outcome variables, $R_{2}$ $=.28-.32$ (see Figure 1). Finally, there was also a moderate correlation between letter sound knowledge and rapid naming at $\mathrm{T} 1(\beta=.34, S E=.10, t=3.29, p<.01)$.

In sum, this first model shows that early letter sound knowledge in kindergarten is an important early predictor of both reading and spelling abilities at the end of first grade.

\subsubsection{Development of Predictor Variables and their Effects on Outcome Variables}

In a next step, we specified a second model (Model 2) with measurements for all four predictor variables at $\mathrm{T} 1-\mathrm{T} 3$ in order to address two separate but interrelated research questions. First, we wanted to investigate the development of the predictor variables and their interrelationships in kindergarten and across school entry. We thus included the autoregressive paths for each predictor variable as well as their cross-level interactions in the model. Second, we wanted to investigate which of the four predictor variables after school entry best predicted children's literacy skills at the end of grade 1 . To address this issue, we included the effects of the predictor variables at $\mathrm{T} 3$ on the outcome variables at $\mathrm{T} 4$ in the model (but not the effects of these variables at T1 or T2). The overall structure of the model is depicted in Figure 2. It showed a moderate fit to the data, $\chi^{2}=101.12 .24, d f=52, p<.001$, $\mathrm{RMSEA}=0.12[0.088,0.159], \mathrm{CFI}=0.86, \mathrm{SRMR}=0.10$. In the following, we will address each of the two main research questions separately.

[Figure 2]

The development of the four predictor variables and their interrelationships are shown on the left-hand side of Figure 2. At T2 (four months before school entry), rime awareness, and rapid naming were predicted only by their corresponding measures at T1(Rime awareness: $\beta=.54, S E=0.10, t=5.23, p<.001$; rapid naming: $\beta=.42, S E=0.14, t=2.98, p$ $<.01)$. Phoneme awareness at T2 was predicted by itself $(\beta=.31, S E=0.10, t=3.20, p<.01)$ and by letter sound knowledge at $\mathrm{T} 1(\beta=.29, S E=0.11, t=2.71, p<.01)$. Letter sound 


\section{Running Head: READING PREDICTORS ACROSS SCHOOL ENTRY}

knowledge was predicted by itself $(\beta=.56, S E=0.12, t=4.68, p<.001)$, and rime awareness $(\beta=.20, S E=0.08, t=2.45, p<.05)$ at $\mathrm{T} 1$.

At T3 (after school entry), rime awareness and letter sound knowledge were predicted only by their respective measures at T2 (Rime awareness: $\beta=.40, S E=0.18, t=2.19, p<$ .05 ; Letter sound knowledge: $\beta=.51, S E=0.18, t=2.89, p<.01)$. Phoneme awareness was predicted by itself $(\beta=.40, S E=0.11, t=3.52, p<.001)$ and by letter sound knowledge $(\beta=$ $.30, S E=0.10, t=2.85, p<.01)$. Rapid naming was predicted by itself $(\beta=.52, S E=0.13, t=$ $3.88, p<.001)$, and by rime awareness at $\mathrm{T} 2(\beta=.20, S E=0.08, t=2.36, p<.05)$. Generally, the amount of explained variance in the predictor variables was moderate to large (see Figure 2), with $R 2$ values varying between $.2-.4$.

In summary, all four predictor variables had strong autoregressive effects at all time points indicating that measurements were reliable and stable across kindergarten and school entry. In addition, the data also revealed some important cross-level interactions. Across the last year before school entry, letter sound knowledge was predicted by rime awareness and had itself an impact on phoneme awareness that persisted across school entry. These results underline the reciprocal relation of phonological awareness abilities and letter sound knowledge. Furthermore, across school entry, rime awareness predicted rapid naming, which shows an early indirect influence of well-developed phonological abilities on more significant reading and spelling predictors.

Turning to the effects of the four prereading skills at T3 on the outcome measures at T4 (shown on the right-hand side of Figure 2), we found that only letter sound knowledge and rapid naming had significant effects on the outcome measures. Specifically, word-picturematching was strongly predicted by rapid naming $(\beta=.38, S E=0.13, t=2.94, p<.01)$; reading fluency was predicted by letter sound knowledge $(\beta=.23, S E=0.11, t=2.09, p<$ 


\section{Running Head: READING PREDICTORS ACROSS SCHOOL ENTRY}

$.05)$ and rapid naming $(\beta=.35, S E=0.13, t=2.81, p<.01)$; spelling was only predicted by letter sound knowledge $(\beta=.19, S E=0.09, t=2.03, p<.05)$. The amount of explained variance in the outcome variables (see Figure 2 ) was surprisingly small, with $R_{2}$ values only ranging between .2-.3., which is smaller than the corresponding $R_{2}$ values in Model 1. This indicates that the predictive value of some of the predictor variables changed from $\mathrm{T} 1$ to $\mathrm{T} 3$.

\subsubsection{Change in Predictor Effects before and after School Entry}

In order to formally compare whether the effects of the predictor measures changed in their strength before and after school entry, we estimated a third model in which the predictive effects from both $\mathrm{T} 1$ and $\mathrm{T} 3$ on outcome variables at $\mathrm{T} 4$ were included at the same time. If predictor variables showed special effects at $\mathrm{T} 1$ that were not captured by their effects at T3 this will manifest itself as a significant additional direct effect and improved model fit.

Before comparing the model with and without direct effects of the predictor variables at T1, we trimmed the model. First, we excluded rime awareness because this variable did not show any significant effects on literacy outcomes at any measurement point. In addition, we also removed all T2 variables, because they were measured right before school entry and therefore irrelevant for the present comparison. This trimmed model (Model 2b) was similar to Model 2, but only included the predictors phoneme awareness, letter sound knowledge, and rapid naming, as well as their autoregressive and cross-level effects between T1 and T3, and the predictive effects of these variables at $\mathrm{T} 3$ on outcome measures at T4. The model showed a good fit to the data, $\chi_{2}=20.22, d f=12, p>.05, \mathrm{RMSEA}=0.10[0.000,0.181], \mathrm{CFI}=0.96$, SRMR $=0.07$, and all of the effects described above were virtually identical to the full model. Similarly, the amount of explained variance was also the same as in the previous model (word-picture-matching: $R_{2}=.28$; reading fluency: $R_{2}=.30$; spelling: $R_{2}=.15$ ).

In a next step, we added the direct effects of the predictor variables at $\mathrm{T} 1$ on the outcome measures at T4 to the model (Model 3, see Figure 3). By comparing Model 3 with 


\section{Running Head: READING PREDICTORS ACROSS SCHOOL ENTRY}

Model $2 \mathrm{~b}$, it is possible to formally evaluate whether the variables at $\mathrm{T} 1 \mathrm{had}$ special effect on the outcome over and above their effects at T3. Model 3 showed an excellent fit to the data $\chi^{2}$ $=0.17, d f=3, p>.05, \mathrm{RMSEA}=0.00[0.000,0.000], \mathrm{CFI}=1.00, \mathrm{SRMR}=0.005)$ and, more importantly, fitted significantly better than Model 2b, $\left.\Delta \chi_{2}=18.36 ; \Delta d f=9 ; p>.05\right)$. In addition, the model was able to explain a larger amount of variance in all three outcome variables, with $R_{2}$ values ranging between $.34-.38$ (see Figure 3).

[Figure 3]

In particular, results of Model 3 showed substantial positive effects of letter sound knowledge measured at T1 on picture-word matching $(\beta=.34, S E=0.11, t=3.13, p<.01)$, reading fluency $(\beta=.28, S E=0.11, t=2.59, p<.05)$, and spelling $(\beta=.49, S E=0.13, t=$ $3.85, p<.001)$ over and above the effects of this variable at T3. This indicates that the predictive effects of letter sound knowledge at T1 are larger than the corresponding effects at T3. Conversely, rapid naming only showed significant predictive effects on word-picturematching $(\beta=.28, S E=0.13, t=2.12, p<.05)$ and reading fluency $(\beta=.28, S E=0.13, t=$ $2.12, p<.05)$ when measured at T3, but not at $\mathrm{T} 1$.

In summary, the analysis confirmed that letter sound knowledge and rapid naming were the most important predictors for children's early reading abilities. In addition, it revealed that the time when these constructs are assessed is of crucial importance: Letter sound knowledge had larger effects on later reading skills before than after school entry. By contrast, rapid naming was only predictive for later reading skills when assessed after school entry. This indicates that it is not only important that but also when children acquire specific skills during reading development. We will come back to this point in the final discussion.

\section{Discussion}

In this study, we compared the effects of reading and spelling predictors before and after school entry on reading and spelling abilities at the end of first grade. The study was 


\section{Running Head: READING PREDICTORS ACROSS SCHOOL ENTRY}

conducted with children learning a transparent orthography, whose educators are not obliged to provide formal literacy training before school entry. Rime awareness, phoneme awareness, letter sound knowledge and rapid naming were assessed at two time points before and one time point shortly after school entry. Word-picture-matching, reading fluency and spelling were assessed at the end of first grade. Stability and cross-level effects of predictors were analyzed across school entry. Furthermore, the predictive effects of the predictors before and after school entry on reading and spelling abilities at the end of first grade were compared.

\subsection{Stability of predictors and cross-level effects}

All measures showed medium to strong autoregressive effects indicating that the underlying abilities were stable during the time periods before and across school entry. Furthermore, an analysis of measurement invariance across time indicated stability of the measured constructs over time as well. However, autoregressive effects of rime awareness decreased across school entry, the corresponding effects of phoneme awareness, letter sound knowledge, and rapid naming remained stable or increased. The increase in effects of phoneme awareness and rapid naming is likely to be explained by an increase in training as these variables are indirectly taught through literacy training in school (Georgiou et al., 2013; Goswami et al., 2005). A decrease of autoregressive effects in rime awareness might be related to a decrease in variability as an increasing number of children master this ability over time (Mann \& Wimmer, 2002; Ziegler \& Goswami, 2005).

In addition, we found some cross-level effects between the early literacy precursor abilities. Before school entry, letter sound knowledge was predicted by rime awareness and letter sound knowledge in turn predicted phoneme awareness. The latter effect persisted across school entry. This points to an often reported, reciprocal relationship between letter sound knowledge and phonological abilities (i.e., Castles \& Coltheart, 2004; Goswami et al., 2005). Our findings indicate that children acquire fine-grained phonological skills (phoneme 


\section{Running Head: READING PREDICTORS ACROSS SCHOOL ENTRY}

awareness) via the acquisition of letter-sound correspondences. This is in line with the assumption that the acquisition of phoneme awareness is influenced by the development of letter knowledge (i.e., Ziegler \& Goswami, 2005). Our study, thus, replicates results from similar studies with children learning a transparent orthography (i.e., Mann \& Wimmer, 2002; Goswami et al., 2005). However, our study adds to the existing knowledge by showing that this reciprocal relationship starts earlier than is typically assumed.

\subsection{Predictive Effects before and after school entry}

An important finding of this study is that letter sound knowledge was consistently the most important predictor for early reading and spelling abilities. In addition, and in contrast to earlier studies on literacy development in German that included letter sound knowledge (i.e., Goswami et al., 2005; Mann \& Wimmer, 2002), the children in our study showed a rather high level of letter sound knowledge even before school entry. It is difficult to evaluate whether this difference is part of a systematic trend over the last decade, because there were few studies that have investigated the development of letter sound knowledge in German. One factor that might have contributed to this is an increasing level of regular contact to letters through the modern media landscape and, as a consequence, an increase in sporadic, early letter sound knowledge training at home and in ECEC facilities (Kuger, Roßbach, \& Weinert, 2013; Lehrl, Ebert, Roßbach, \& Weinert, 2012; Niklas \& Schneider, 2013).

Another important finding of this study is that letter sound knowledge was found particularly helpful for later reading and spelling skills when it was acquired early. Letter sound knowledge at $\mathrm{T} 1$ showed substantial direct effects on all outcome variables over and above the corresponding effects at T3. Thus, in line with our expectations, the predictive effect of letter sound knowledge decreased across school entry, which might be related to the explicit training of letter-sound knowledge at the beginning of first grade. 


\section{Running Head: READING PREDICTORS ACROSS SCHOOL ENTRY}

Moreover, and also in line with our expectations, rapid naming became more relevant to the prediction of reading abilities across time. While rapid naming did not predict any of the outcome variables before school entry it emerged as the most powerful predictor for both word-picture-matching abilities and reading fluency after children had entered school. Again, this shift is presumably associated with the onset of formal reading instruction which indirectly fosters serial processing abilities and, thus, the mechanism underlying both rapid naming and reading (Georgiou et al., 2013). In contrast to the findings of Moll and colleagues (2014) in grade 4, we did not find effects of rapid naming on spelling, which might indicate that the writing process is not serialized at the end of first grade yet.

Contrary to our expectations, predictive effects of phoneme awareness did not increase across school entry. In fact, once cross-level effects with letter sound knowledge were controlled for, the effect of phonological variables was surprisingly small in our study. Similar patterns were reported by studies with Finnish and Dutch (Hulme et al., 2015; Torppa et al., 2010; Van Viersen et al., 2018), which indicates that letter sound knowledge and rapid naming might play a more important role in transparent than in opaque languages.

Moreover, although rime awareness did not predict reading or spelling, it did predict the knowledge of letter sound correspondences during the last kindergarten year and rapid naming across school entry. Thus, rime awareness had an indirect impact on literacy development that was relevant for the development of significant precursor skills. Overall, rime awareness was more relevant as a predictor at earlier stages of literacy development (T1 and T2) than at later ones, which is in line with previous literature on literacy development in transparent orthographies (Castles \& Coltheart, 2004; Goswami et al., 2005; Ziegler \& Goswami, 2005).

It is important to note, however, that our study also has some limitations with regard to evaluating the impact of different precursor skills and their change over time. In particular, by 


\section{Running Head: READING PREDICTORS ACROSS SCHOOL ENTRY}

the very design of our study, the variability of some variables decreased across school entry because children became better with increasing age. This is unavoidable in a longitudinal study in which the same measures are used at all measurement points. In this setting, tasks have to be easy enough so that they could be administered even to very young children. Although our tests for measurement invariance indicated that all variables still measured the same constructs, it would be advisable to use an adaptive and incremental study design in future studies (i.e., Embretson, 2010).

\subsection{Conclusion}

In conclusion, we found that letter sound knowledge was an important early predictor for German children's early reading and spelling skills before school entry, while rapid naming was the most important predictor for reading abilities after school entry. Phoneme awareness did not predict reading or spelling abilities after cross-level effects when letter sound knowledge was controlled for. Our findings, thus, demonstrate that the impact of different literacy precursor skills in children learning a transparent orthography differ before and after school entry. Further research is needed in order to investigate the developmental trajectories of different precursor abilities and how to implement them in early education curricula.

\section{Acknowledgments}

We thank Julia Mann, Felix Klapproth and Elisabeth Klose for their support in data collection. 


\section{Running Head: READING PREDICTORS ACROSS SCHOOL ENTRY}

\section{References}

Bradley, L., \& Bryant, P. (1978). Difficulties in auditory organization as a possible cause of reading backwardness. Nature.271, 746-748. doi: 10.1038/271746a0.

Caravolas, M., Hulme, C., \& Snowling, M. J. (2001). The foundations of spelling ability: Evidence from a 3-year longitudinal study. Journal of Memory and Language, 45(4), 751-774. doi: 10.1006/jmla.2000.2785

Caravolas, M., Lervåg, A., Mousikou, P., Efrim, C., Litavský, M., Onochie-Quintanilla, E., ... \& Hulme, C. (2012). Common patterns of prediction of literacy development in different alphabetic orthographies. Psychological Science, 23(6), 678-686. doi: $10.1177 / 0956797611434536$

Caravolas, M., Lervåg, A., Defior, S., Málková, G. S., \& Hulme, C. (2013). Different patterns, but equivalent predictors, of growth in reading in consistent and inconsistent orthographies. Psychological Science, 24, 1398-1407. doi: $10.1177 / 0956797612473122$

Castles, A., \& Coltheart, M. (2004). Is there a causal link from phonological awareness to success in learning to read? Cognition, 91(1), 77-111.doi:10.1016/S00100277(03)00164-1.

Cheung, G. W., \& Rensvold, R. B. (2002). Evaluating goodness-of-fit indexes for testing measurement invariance. Structural equation modeling, 9(2), 233-255.

Cunningham, A. E., \& Stanovich, K. E. (1997). Early reading acquisition and its relation to reading experience and ability 10 years later. Developmental Psychology, 33(6), 934945. doi: $10.1037 / 0012-1649.33 .6 .934$

Embretson, S. E. (2000). Multidimensional measurement from dynamic tests: Abstract reasoning under stress. Multivariate Behavioral Research, 35(4), 505-542. doi: 10.1207/S15327906MBR3504_05 
Running Head: READING PREDICTORS ACROSS SCHOOL ENTRY

Ennemoser, M., Marx, P., Weber, J., \& Schneider, W. (2012). Spezifische

Vorläuferfertigkeiten der Lesegeschwindigkeit, des Leseverständnisses und des

Rechtschreibens. Zeitschrift für Entwicklungspsychologie und Pädagogische

Psychologie, 44, 53-67. doi: 10.1026/0049-8637/a000057

Esser, G., Wyschkon, A. (2016). Basisdiagnostik Umschriebener Entwicklungsstörungen im Vorschulalter - Version III (BUEVA-III). Göttingen: Hogrefe.

Georgiou, G. K., Parrila, R., Cui, Y., \& Papadopoulos, T. C. (2013). Why is rapid automatized naming related to reading?. Journal of experimental child psychology, $115(1), 218-225$.

Georgiou, G. K., Papadopoulos, T. C., \& Kaizer, E. L. (2014). Different RAN components relate to reading at different points in time. Reading and Writing, 27(8), 1379-1394.

Goswami, U., Ziegler, J. C., \& Richardson, U. (2005). The effects of spelling consistency on phonological awareness: A comparison of English and German. Journal of Experimental Child Psychology, 92(4), 345-365. doi: 10.1016/j.jecp.2005.06.002.

Holopainen, L., Ahonen, T., Tolvanen, A., \& Lyytinen, H. (2000). Two alternative ways to model the relation between reading accuracy and phonological awareness at preschool age. Scientific Studies of Reading, 4(2), 77-100. doi:

10.1207/S1532799XSSR0402_01

Hulme, C., Nash, H. M., Gooch, D., Lervåg, A., \& Snowling, M. J. (2015). The foundations of literacy development in children at familial risk of dyslexia. Psychological Science, 26(12), 1877-1886. doi: 10.1177/0956797615603702

Kauschke, C., \& Siegmüller, J. (2010). Patholinguistische Diagnostik bei Sprachentwicklungsstörungen (PDSS) (Vol. 4). München: Elsevier, Urban \& Fischer Verlag. 


\section{Running Head: READING PREDICTORS ACROSS SCHOOL ENTRY}

Kessler, B., Pollo, T. C., Treiman, R., \& Cardoso-Martins, C. (2013). Frequency analyses of prephonological spellings as predictors of success in conventional spelling. Journal of Learning Disabilities, 46(3), 252-259. doi: 10.1177/0022219412449440

Kuger, S., Rossbach, H.-G., Weinert, S. (2013). Early literacy support in institutional settings - A comparison of quality of support at the classroom level and the individual child level. In Pfost, M.; Artelt, C.; Weinert, S.(Eds.), Schriften aus der Fakultät Humanwissenschaften der Otto-Friedrich-Universität Bamberg: Vol. 14. The Development of Reading Literacy from Early Childhood to Adolescence: Empirical findings from the Bamberg BiKS longitudinal studies (pp.63 - 93).

Lehrl, S., Ebert, S., Roßbach, H. G., \& Weinert, S. (2012). Die Bedeutung der familiären Lernumwelt für Vorläufer schriftsprachlicher Kompetenzen im Vorschulalter. Zeitschrift für Familienforschung, 24(2), 115-133.

Lenhard, W., Schneider, W., \& Schneider, W. (2006). ELFE 1-6: ein Leseverständnistest für Erst-bis Sechstklässler. Göttingen: Hogrefe.

Leppänen, U., Aunola, K., Niemi, P., \& Nurmi, J. E. (2008). Letter knowledge predicts Grade 4 reading fluency and reading comprehension. Learning and Instruction, 18(6), 548564. doi: 10.1016/j.learninstruc.2007.11.004

Lervåg, M., Lyster, S. A. H., \& Hulme, C. (2012). Phonological skills and their role in learning to read: a meta-analytic review. Psychological bulletin, 138(2), 322- 352. doi: $10.1037 / \mathrm{a} 0026744$

Mann, V., \& Wimmer, H. (2002). Phoneme awareness and pathways into literacy: A comparison of German and American children. Reading and Writing, 15(7), 653682. doi: 10.1023/A:1020984704781

May, P., Vieluf, U., \& Malitzky, V. (2002). HSP 1-9: Diagnose orthographischer Kompetenz zur Erfassung der grundlegenden Rechtschreibstrategien mit der Hamburger 
Running Head: READING PREDICTORS ACROSS SCHOOL ENTRY

Schreibprobe: Neustandardisierung 2001. Stuttgart: VPM Verlag für Pädagogische Medien.

Moll, K., \& Landerl, K. (2010). Lese-und Rechtschreibtest (SLRT-II). Weiterentwicklung des Salzburger Lese-und Rechtschreibtests (SLRT). (Reading and Spelling Test SLRT-II). Bern: Hans Huber.

Moll, K., Ramus, F., Bartling, J., Bruder, J., Kunze, S., Neuhoff, N., ... \& Landerl, K. (2014). Cognitive mechanisms underlying reading and spelling development in five European orthographies. Learning and Instruction, 29, 65-77. doi: 10.1016/j.learninstruc.2013.09.003

Murphy, K. A., \& Farquharson, K. (2016). Investigating profiles of lexical quality in preschool and their contribution to first grade reading. Reading and Writing, 29(9), 1745-1770. doi: https://doi.org/10.1007/s11145-016-9651-y

Muter, V., Hulme, C., Snowling, M. J., \& Stevenson, J. (2004). Phonemes, rimes, vocabulary, and grammatical skills as foundations of early reading development: evidence from a longitudinal study. Developmental Psychology, 40(5), 665 -681. doi: 10.1037/00121649.40.5.665.

Näslund, J. C., \& Schneider, W. (1996). Kindergarten letter knowledge, phonological skills, and memory processes: Relative effects on early literacy. Journal of Experimental Child Psychology, 62(1), 30-59. doi: 10.1006/jecp.1996.0021

Niklas, F., \& Schneider, W. (2013). Home literacy environment and the beginning of reading and spelling. Contemporary Educational Psychology, 38(1), 40-50. doi: 10.1016/j.cedpsych.2012.10.001

Pauly, H., Linkersdörfer, J., Lindberg, S., Woerner, W., Hasselhorn, M., \& Lonnemann, J. (2011). Domain-specific rapid automatized naming deficits in children at risk for 


\section{Running Head: READING PREDICTORS ACROSS SCHOOL ENTRY}

learning disabilities. Journal of Neurolinguistics, 24(5), 602-610. doi:

10.1016/j.jneuroling.2011.02.002

Rosseel, Y. (2012). Lavaan: An R package for structural equation modeling and more. Version 0.5-12 (BETA). Journal of Statistical Software, 48(2), 1-36. URL http://www.jstatsoft.org/v48/i02/.

Schatschneider, C., Fletcher, J. M., Francis, D. J., Carlson, C. D., \& Foorman, B. R. (2004). Kindergarten prediction of reading skills: A longitudinal comparative analysis. Journal of Educational Psychology, 96(2), 265-282. doi: 10.1037/00220663.96.2.265

Schneider, W., Blanke, I., Faust, V., \& Küspert, P. (2011). Würzburger Leise LeseprobeRevision (WLLP-R). Ein Gruppentest für die Grundschule (revised version). Göttingen: Hogrefe.

Senatsverwaltung für Bildung, Jugend und Wissenschaft (2014). Berliner Bildungsprogramm für Kitas und Kindertagespflege. Retrieved from: http://www.gewberlin.de/public/me-dia/berliner_bildungsprogramm_2014.pdf

Senatsverwaltung für Bildung, Jugend und Wissenschaft (2017). Berliner Rahmenlehrplan 110. Retrieved from: https://bildungsserver.berlinbrandenburg.de/fileadmin/bbb/unterricht/rahmenlehrplaene/Rahmenlehrplanprojekt/a mtliche_Fassung/Teil_C_Deutsch_2015_11_10_WEB.pdf

Stock, C., Marx, P., Schneider, W., \& Schneider, W. (2003). BAKO 1-4: Basiskompetenzen für Lese-Rechtschreibleistungen: ein Test zur Erfassung der phonologischen Bewusstheit vom ersten bis vierten Grundschuljahr. Göttingen: Beltz.

Torppa, M., Lyytinen, P., Erskine, J., Eklund, K., \& Lyytinen, H. (2010). Language development, literacy skills, and predictive connections to reading in Finnish 
Running Head: READING PREDICTORS ACROSS SCHOOL ENTRY

children with and without familial risk for dyslexia. Journal of Learning Disabilities, 43(4), 308-321. doi: 10.1177/0022219410369096

van Viersen, S., de Bree, E., Maassen, B., van der Leij, A., de Jong, P.F. (2018). Pathways into Literacy: The Role of Early Oral Language Abilities and Family Risk for Dyslexia. Psychological Science, 29 (3), pp. 418-428. doi:

$10.1177 / 0956797617736886$

Wagensveld, B., van Alphen, P., Segers, E., \&Verhoeven, L. (2012). The nature of rhyme processing in preliterate children. British Journal of Educational Psychology, 82(4), 672-689. doi: 10.1111/j.2044-8279.2011.02055.x

Ziegler, J. C., \& Goswami, U. (2005). Reading acquisition, developmental dyslexia, and skilled reading across languages: A psycholinguistic grain size theory. Psychological Bulletin, 131(1), 3-29. doi: 0.1037/0033-2909.131.1.3

Ziegler, J. C., Bertrand, D., Tóth, D., Csépe, V., Reis, A., Faísca, L., \& Blomert, L. (2010). Orthographic depth and its impact on universal predictors of reading: A crosslanguage investigation. Psychological Science. 21(4) 551-559, doi:

$10.1177 / 0956797610363406$ 
Table 1. Means, Standard Deviations Maximums and Reliability Coefficients of Outcome Variables, Predictors and Covariates.

\begin{tabular}{lcccc}
\hline Variables & $M(S D)$ & Range & Max & Reliability \\
\hline Outcome Variables & & & & \\
Word-Picture-Matching (T4) & $37.32(18.24)$ & $7-78$ & 80 & $\alpha=.97$ \\
$\quad$ standardized value (percent & $39.60(30.08)$ & $1-96$ & 100 & \\
range) & $21.77(17.27)$ & $0-72$ & 156 & $r=.90$ \\
Reading Fluency (T4) & $60.22(27.64)$ & $3-98$ & 100 & \\
$\quad$ standardized value (percent & $46.75(10.45)$ & $0-60$ & 60 & $\alpha=.96$ \\
range) & $48.92(9.37)$ & $24-70$ & 80 & \\
Spelling (T4) & & & & \\
$\quad$ standardized value (T-Value) & $26.95(3.61)$ & $17-32$ & 32 & $\alpha=.68$ \\
Predictors & $27.75(3.49)$ & $17-32$ & 32 & $\alpha=.72$ \\
Rime Awareness (T1) & $28.91(3.03)$ & $19-32$ & 32 & $\alpha=.74$ \\
Rime Awareness (T2) & $18.21(4.54)$ & $10-29$ & 32 & $\alpha=.66$ \\
Rime Awareness (T3) & $20.34(5.14)$ & $10-31$ & 32 & $\alpha=.57$ \\
Phoneme Awareness (T1) & $21.73(5.29)$ & $10-29$ & 32 & $\alpha=.57$ \\
Phoneme Awareness (T2) & $23.52(5.60)$ & $10-32$ & 32 & $\alpha=.84$ \\
Phoneme Awareness (T3) & $27.12(4.52)$ & $15-32$ & 32 & $\alpha=.84$ \\
Letter Knowledge (T1) & $29.62(2.46)$ & $20-32$ & 32 & $\alpha=.70$ \\
Letter Knowledge (T2) & $0.71(0.17)$ & $0.32-1.10$ & -- & -- \\
Letter Knowledge (T3) & $0.76(0.16)$ & $0.32-1.10$ & -- & - \\
RAN Objectsa (T1) & $0.87(0.22)$ & $0.32-1.55$ & -- & -- \\
RAN Objectsa (T2) & & & & \\
RAN Objectsa (T3) & & &
\end{tabular}

Note. a number of correct responses per second. 


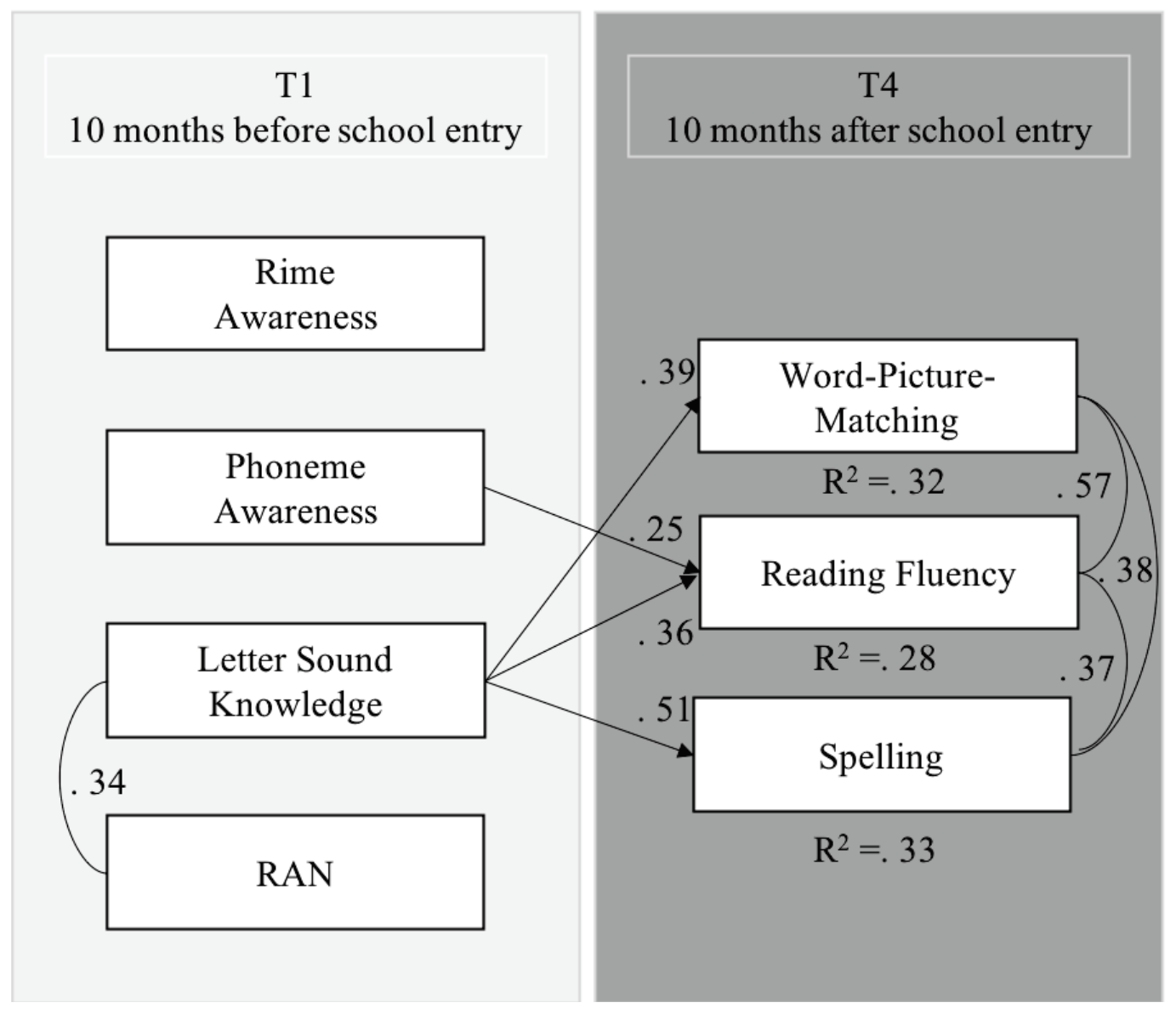

Figure 1. Paths of significant effects of first SEM model with predictors at T1 predicting reading and spelling abilities at T4. 


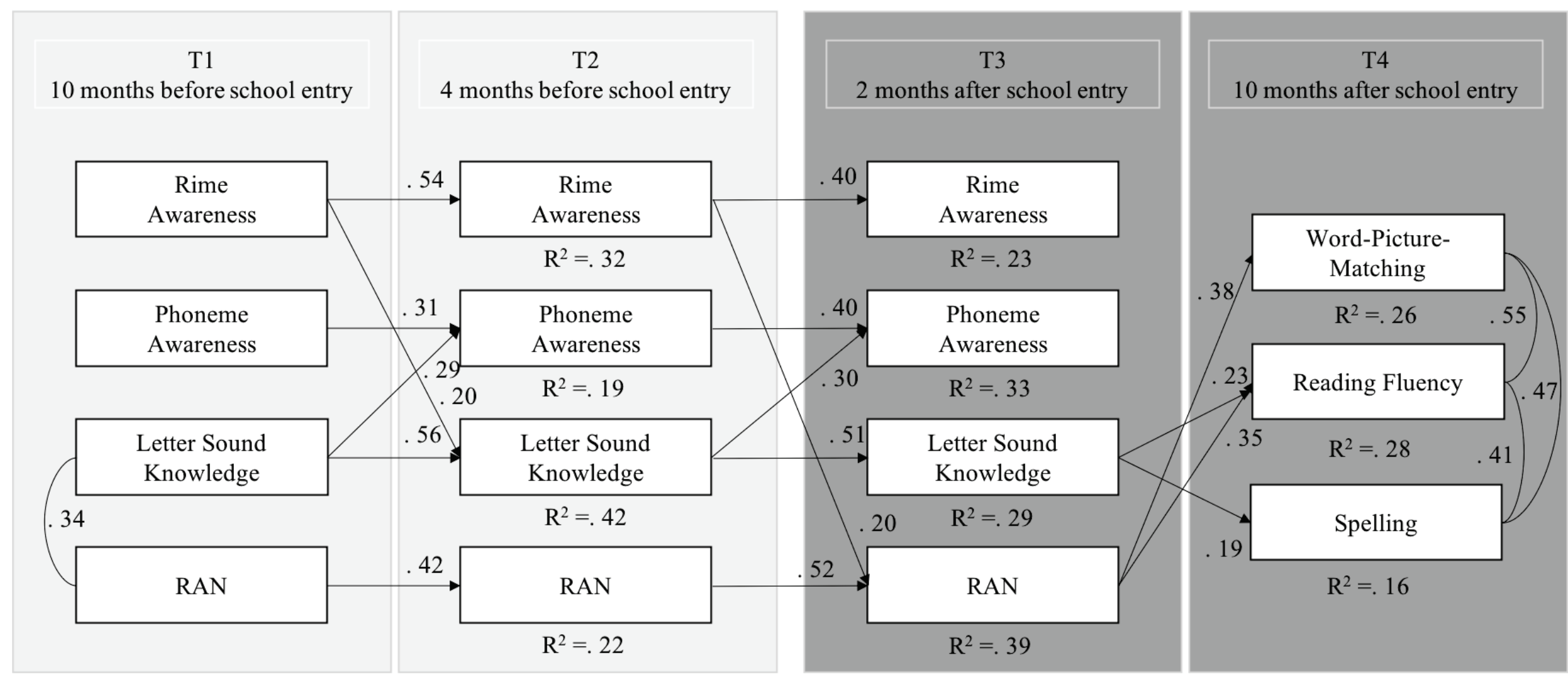

Figure 2. Paths of significant effects of second path model with cross-level and autoregressive effects of predictors and predictors at T3 predicting reading and spelling abilities at $\mathrm{T} 4$. 


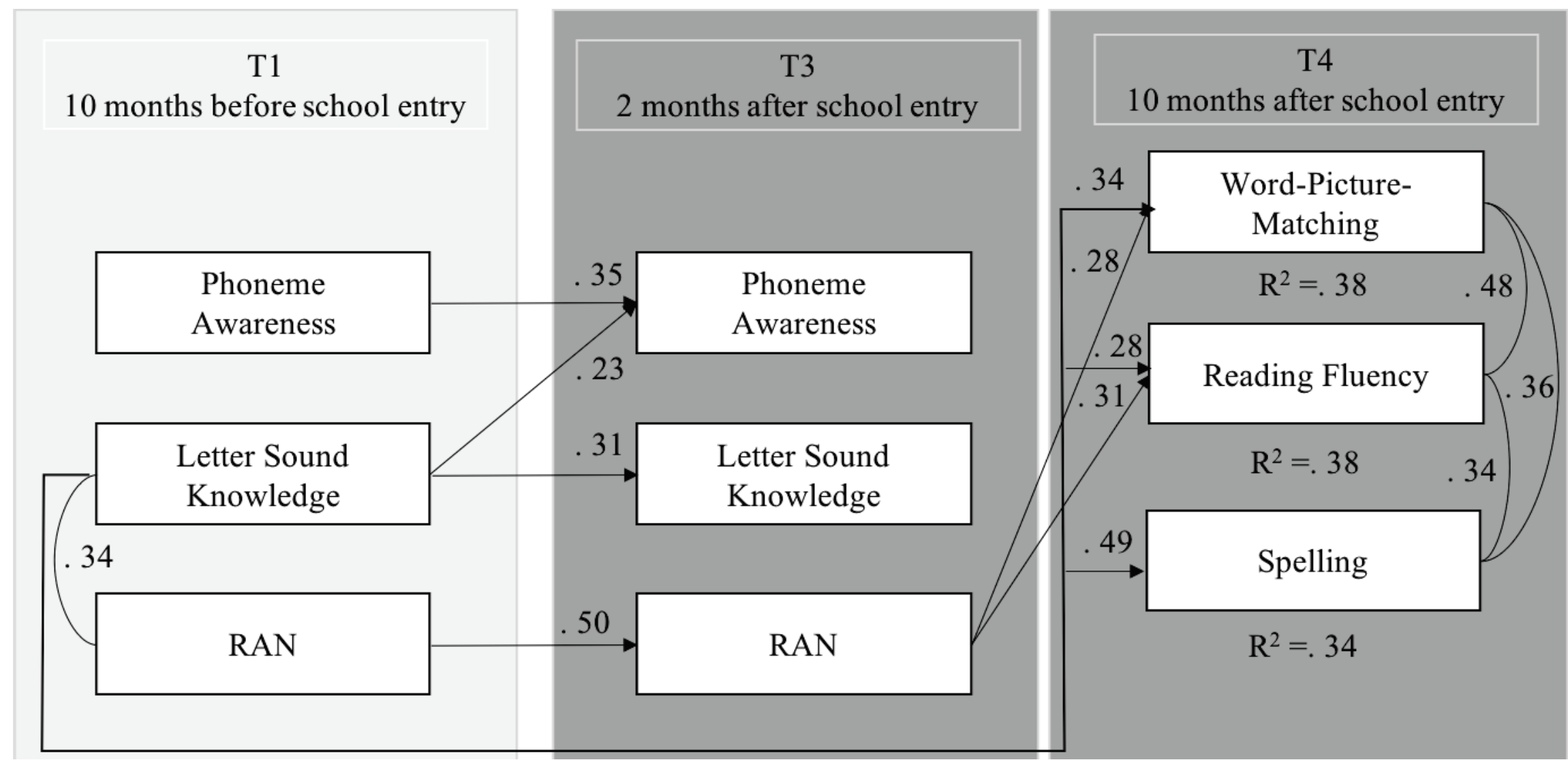

Figure 3. Paths of significant effects of third path model with predictors at T1 and T4 predicting reading and spelling abilities at T4. 
Effects of Reading and Spelling Predictors Before and After School Entry: Evidence from a German Longitudinal Study

Alexandra M. A. Schmitterer1 and Sascha Schroeder2

1DIPF | Leibniz Institute for Research and Information in Education, Frankfurt am Main 2Max Planck Institute for Human Development, Berlin

Disclaimer: This PDF document is a copy of the final version of the manuscript's supplementary material that was subsequently accepted for publication by the Elservier Journal "Learning and Instruction". This is a peer-reviewed post-print version, that has not been subjected to any additional copy-editing or journal-specific formatting.

Cite this article as:

Schmitterer, A. M.A., \& Schroeder, S. (2019). Effects of reading and spelling predictors before and after school entry: Evidence from a German longitudinal study. Learning and Instruction, 59, 46-53. doi: 10.1016/j.learninstruc.2018.09.005 


\section{Supplementary Material}

Table S1. Differences between children that remained in kindergarten (group 1), had missings (group 2) and children that had full data sets (group 3)

\begin{tabular}{lcccccc}
\hline & Group 1 & Group 2 & Group 3 & $F(2,102)$ & $p$ & Post-hocb \\
& $M(S D)$ & $M(S D)$ & $M(S D)$ & & & \\
\hline Age (in months) & $53.09(3.21)$ & $55.89(3.90)$ & $57.10(3.19)$ & 11.97 & $<.001$ & $1<2 \& 3$ \\
SES (HISEI) & $62.20(12.44)$ & $64.60(11.31)$ & $68.19(11.28)$ & 2.28 & n.s. & -- \\
Mother's Education & $6.23(1.38)$ & $6.53(0.87)$ & $6.80(0.88)$ & 2.75 & n.s. & -- \\
Expressive Vocabularya & $43.67(5.33)$ & $47.36(8.64)$ & $50.69(5.53)$ & 7.94 & $<.001$ & $1<3$ \\
\hline
\end{tabular}

Note. Group 1: $N=22$, group 2: $N=17$, group 3: $N=65$; results from one-way ANOVAs are reported; a standardized T-values; b significant group differences, all $t \mathrm{~s}>2.3$, all $p \mathrm{~s}<.05$. 
Table S2. Skewness and Kurtosis for Outcome Variables Predictors and Covariate

\begin{tabular}{lcc}
\hline Variables & skewness & kurtosis \\
\hline Outcome Variables & & \\
Word-Picture-Matching (raw values) & 0.52 & 2.69 \\
Word-Picture-Matching (standardized percent range) & 0.60 & 2.19 \\
Reading Fluency (raw values) & 1.18 & 3.53 \\
Reading Fluency (standardized percent range) & -0.09 & 1.99 \\
Spelling (raw values) & -2.65 & 11.15 \\
Spelling (standardized T-value) & -0.30 & 3.53 \\
Predictors & & \\
Rime Awareness (T1) & -0.82 & 3.31 \\
Rime Awareness (T2) & -1.13 & 3.95 \\
Rime Awareness (T3) & -1.40 & 4.46 \\
Phoneme Awareness (T1) & 0.32 & 2.69 \\
Phoneme Awareness (T2) & -0.08 & 2.27 \\
Phoneme Awareness (T3) & -0.49 & 2.30 \\
Letter Knowledge (T1) & -0.26 & 2.25 \\
Letter Knowledge (T2) & -0.88 & 2.95 \\
Letter Knowledge (T3) & -1.72 & 6.39 \\
RAN Objects (T1; speed/accuracy ratio) & 0.20 & 2.71 \\
RAN Objects (T2; speed/accuracy ratio) & -0.09 & 2.91 \\
RAN Objects (T3; speed/accuracy ratio) & 0.08 & 3.66 \\
\hline
\end{tabular}


Table S3. Correlations between Predictors and Outcome Variables

\begin{tabular}{|c|c|c|c|c|c|c|c|c|c|c|c|c|c|c|c|}
\hline Variables & 1. & 2. & 3. & 4. & 5. & 6. & 7. & 8. & 9. & 10. & 11. & 12. & 13. & 14. & 15. \\
\hline 1. T1 Rime Awareness & - & & & & & & & & & & & & & & \\
\hline 2. T1 Phoneme Awareness & .13 & - & & & & & & & & & & & & & \\
\hline 3. T1 Letter Sound Knowledge & .04 & .07 & - & & & & & & & & & & & & \\
\hline 4. T1 Rapid Naming & .11 & .19 & .33 & - & & & & & & & & & & & \\
\hline 5. T2 Rime Awareness & .53 & .13 & .05 & .18 & - & & & & & & & & & & \\
\hline 6. T2 Phoneme Awareness & .11 & .35 & .28 & .09 & .14 & - & & & & & & & & & \\
\hline 7. T2 Letter Sound Knowledge & .25 & .22 & .59 & .26 & .21 & .26 & - & & & & & & & & \\
\hline 8. T2 Rapid Naming & .02 & .16 & .19 & .46 & -.05 & .25 & .11 & - & & & & & & & \\
\hline 9. T3 Rime Awareness & .45 & .16 & .27 & .21 & .44 & .15 & .05 & .23 & - & & & & & & \\
\hline 10. T3 Phoneme Awareness & .03 & .44 & .36 & .45 & .08 & .49 & .24 & .26 & .20 & - & & & & & \\
\hline 11. T3 Letter Sound Knowledge & .12 & .25 & .37 & .30 & .29 & .38 & .51 & .28 & .26 & .25 & - & & & & \\
\hline 12. T3 Rapid Naming & .25 & .34 & .34 & .59 & -.05 & .19 & .08 & .55 & .20 & .34 & .22 & - & & & \\
\hline 13. T4 Word Picture Matching & .08 & .27 & .47 & .39 & .24 & .21 & .43 & .30 & .23 & .30 & .33 & .46 & - & & \\
\hline 14. T4 Reading Fluency & .08 & .31 & .43 & .31 & .22 & .26 & .39 & .31 & .29 & .31 & .38 & .46 & .88 & - & \\
\hline 15. T4 Spelling & .11 & .15 & .53 & .28 & .24 & .20 & .27 & .27 & .29 & .21 & .32 & .29 & .71 & .66 & - \\
\hline
\end{tabular}

Note. T1 = 10 months before school entry; T2 = four months before school entry; T3 = two months after school entry; T4 = 10 months after school entry; coefficients in grey are not significant; coefficients in italic are cross level effects; coefficients in bold and italic are within-construct correlations across time. 